\title{
APPLICATION, PRACTICALITY, AND THE EYE OF THE BEHOLDER
}

"All innovation is evolutionary." [Eric Weiner (2016) The Geography of Genius.]

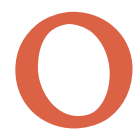

n October $3^{\text {rd }}$, the winner of this year's Nobel Prize for Physiology or Medicine was announced as

Yoshinori Ohsumi, a Professor in the Tokyo Institute of Technology, for his "discoveries of mechanisms for autophagy”. In the world press, he was widely quoted as describing himself as, "a basic researcher in yeast." Despite the fundamental nature of his work with genetically engineered Saccharomyces cerevisiae, in which he studied genes and proteins in vacuoles and autophagosomes, his discovery of proteins and protein complexes involved in autophagy may provide a critical insight into cellular processes in human cancer and syndromes such as $\mathrm{Alz}$ heimer's Disease (Nobel Assembly 2016). Like many mycologists working today, his studies advanced from preliminary observations with light and electron microscopy to the sophisticated genetic and analytical techniques of the genomics era.

For those who aspire to glory, mycology might seem like an odd choice of careers, but the new millennium has been very rewarding for researchers using brewers' yeast as a model system. Ohsumi's Nobel is the fourth to be awarded in the past 15 years, with Physiology or Medicine prizes: in 2001 going to Hartwell, Hunt, and Nurse for their discoveries of "key regulators of the cell cycle”; in 2009 to Blackburn, Greider and Szostak "for the discovery of how chromosomes are protected by telomeres and the enzyme telomerase"; in 2013 to Rothman, Schekman, and Südhof "for their discoveries of machinery regulating vesicle traffic, a major transport system in our cells"; and the 2006 Nobel Prize in Chemistry to Kornberg, "for his studies of the molecular basis of eukaryotic transcription" (citations from NobelPrize.org).

In the press conference after his award was announced, Ohsumi said, "My work with yeast stemmed from a personal desire to undertake work that is unique and doesn't follow the intellectual trends of the day." He noted a reluctance in young scientists to work on research that did not conform with current trends (Tokyo Tech News 2016).

Ohsumi's award and remarks are instructive. All researchers in mycology

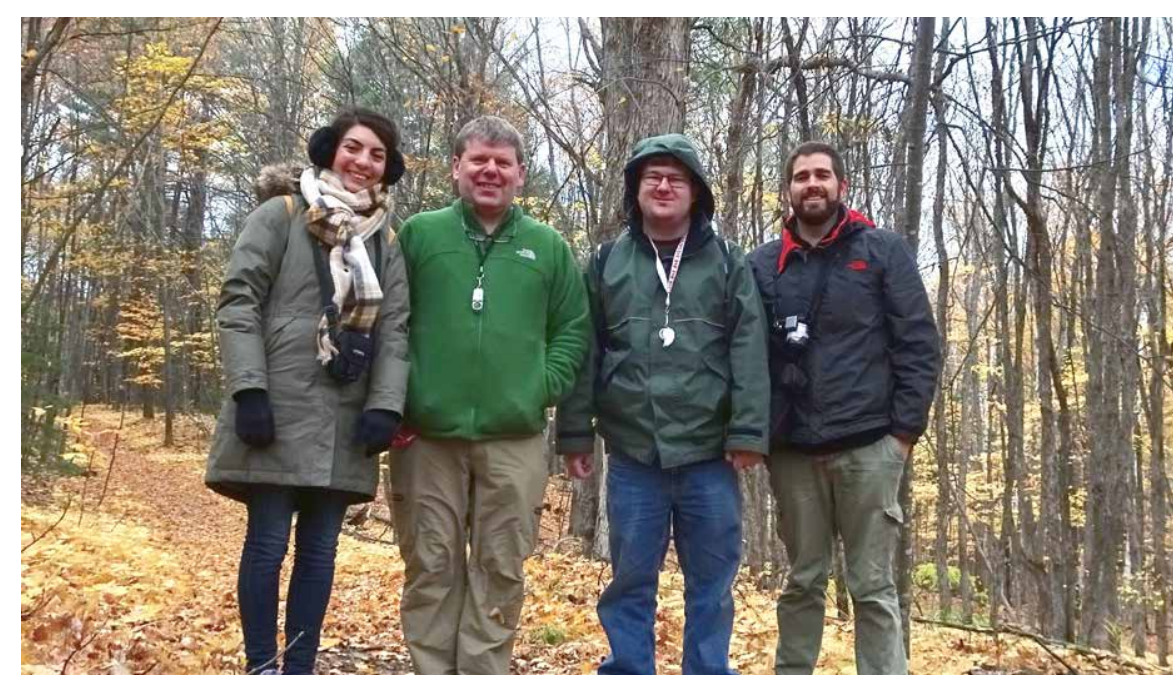

Collecting in the MacNamara Woods, Arnprior, Ontario, Canada, 26 October 2016. Neriman Yilmaz, Keith Seifert, Jonathan Mack and Cobus Visagie (left to right). Photo: Courtesy Neriman Yilmaz.

face questions about the practical relevance of what they do. Even the most esoteric of academics considers their work important, even if they are unable to draw a direct line from results to a concrete application or benefit. Predicting the successful applications of research results has a lot in common with predicting the outcomes of evolution: there are many lineages and nodes of unknown significance, many extinct lineages, and the occasional spectacular success.

When I was a student, I met several respected scientists who proclaimed the relevance of their applied research and its practical outcomes. From my naive perspective, their work often seemed boring and unimaginative, aiming at incremental improvements rather than fundamental discoveries. More disturbing was a tendency to label research without obvious applications as trivial and a waste of time and money. My perspectives changed as I matured and I realized that science is a continuum, as results, data, and ideas pass from one discipline to another, and from one generation to another. Practicality, it always seemed to me, is in the eye of the beholder, the eye of the person with the problem. We can't be proactive about solving problems we are unaware of, but we can be proactive in developing information and technology that can be applied when new problems are discovered.

Although Yoshinori Ohsumi is a rare recent example of a solo Nobel winter, he was careful to acknowledge his collaborators, post docs, and students in his comments to the press. Of the four key papers listed by the Nobel Committee (see box), he is not the first author on any of them. Mycologists are accustomed to research papers with long lists of authors, which result from collaborations among different subdisciplines of mycology, but also with collaborators who would never consider themselves mycologists and would never attend a mycological conference; bioinformaticians, chemists, ecologists, industrial hygienists, medical doctors, space scientists, etc. Our role as scientists remains the same as it has always been - to develop our own body of expertise and contribute to our own field. More and more we have opportunities to contribute to the solution of problems beyond our own immediate vision. We must be alert for these. This is good for our careers and good for mycology.

The Nobel Committee, with this Prize and many others, rewards breakthroughs in understanding rather than revolutionary products. We don't know whether illumination provided by Yoshinori Ohsumi and his team using their beloved 


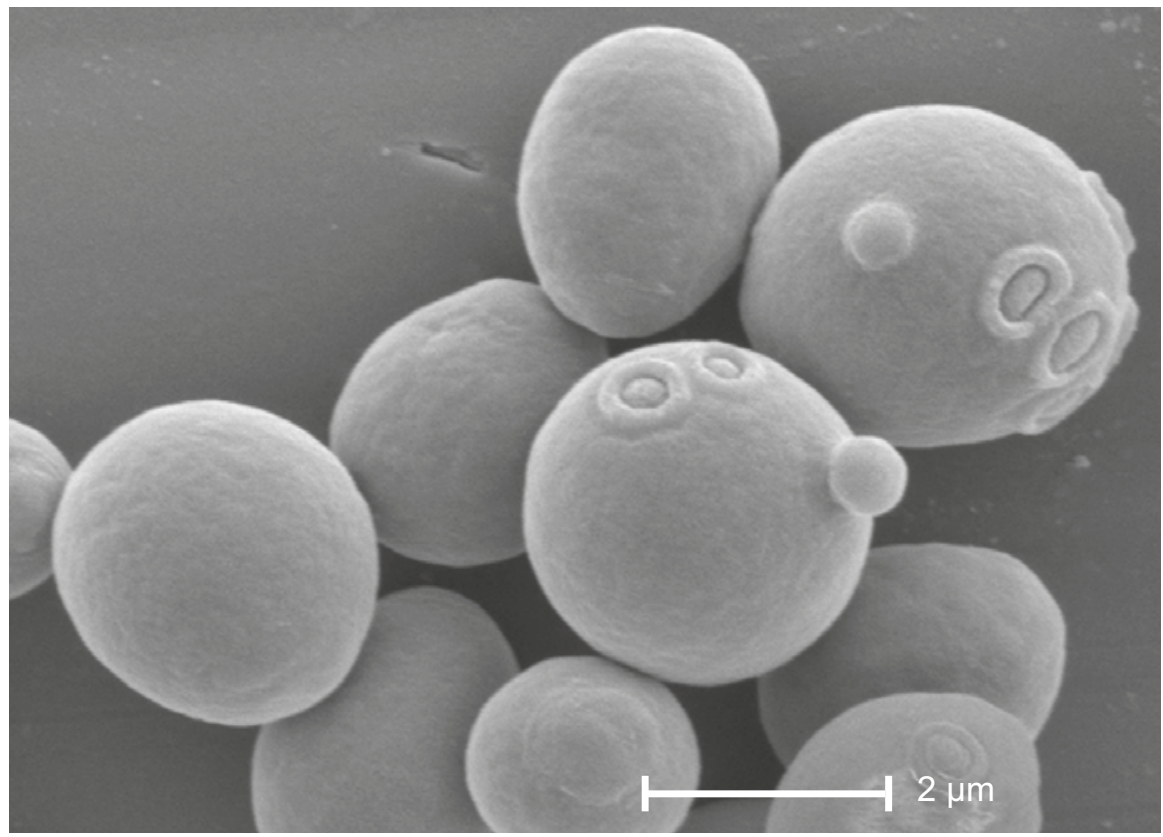

Cells of the baker's yeast (Saccharomyces cerevisiae) showing buds and budding scars. Since 2001 six Nobel prices have been awarded to researchers who used this yeast as a model. Photo courtesy Wally Müller, Utrecht University.

Saccharomyces will lead to therapies for the 14 million new cases and 8.2 million deaths annually caused by cancer (World Health Organization 2013) or the $50 \%$ of us who will suffer from forms of dementia such as Alzheimer's by the age of 85 (Ingram 2014). But to quote Ohsumi, "If nothing else, I want everyone to understand that the nature of fundamental research is such that it develops in ways that are sometimes not initially anticipated but have an immense and beneficial impact on society."

Science is now a team sport. The teams occur within a discipline, across disciplines and often include researchers from many countries. It is not only important to be a good [insert subdiscipline here] mycologist and a good general mycologist, but also to be a good biologist and a good scientist. If we do this, there is a significant chance to make a positive contribution to society and we can worry about prizes later.

Ingram J (2014) The End of Memory: a natural history of Alzheimer's and aging. Toronto: Harper Collins.

Nobel Assembly at Karolinska Institutet (2016) Press release. http://www.nobelprize.org/ nobel_prizes/medicine/laureates/2016/press. html
Tokyo Tech News (2016) Press conference for Yoshinori Ohsumi, 2016 Nobel laureate in medicine. http://www.titech.ac.jp/english/ news/2016/036465.html

World Health Organization (2013) 10 facts about cancer. http://www.who.int/features/factfiles/ cancer/en/

Key publications of Yoshinori Obsumi cited by the Nobel Assembly, by year of publication

Takeshige K, Baba M, Tsuboi S, Noda T, Ohsumi Y (1992) Autophagy in yeast demonstrated with proteinase-deficient mutants and conditions for its induction. Journal of Cell Biology 119: 301-311.

Tsukada M, Ohsumi Y (1993) Isolation and characterization of autophagy-defective mutants of Saccharomyces cervisiae. FEBS Letters 333: 169-174.

Mizushima N, Noda T, Yoshimori T, Tanaka Y, Ishii T, George MD, Klionsky DJ, Ohsumi M, Ohsumi Y (1998) A protein conjugation system essential for autophagy. Nature 395: 395-398.

Ichimura Y, Kirisako T, Takao T, Satomi Y, Shimonishi Y, Ishihara N, Mizushima N, Tanida I, Kominami E, Ohsumi M, Noda T, Ohsumi Y (2000) A ubiquitin-like system mediates protein lipidation. Nature 408: 488-492.

Keith A. Seifert President

International Mycological Association Biodiversity (Mycology and Microbiology) Agriculture and Agri-Food Canada 960 Carling Avenue

Ottawa, Ontario K1A 0C6 Canada (keith.seifert@agr.gc.ca) 